\title{
The effects of fluoxetine on the subjective and physiological effects of 3,4-methylenedioxymethamphetamine (MDMA) in humans
}

\author{
Manuel Tancer $\cdot$ Chris-Ellyn Johanson
}

Received: 13 July 2006 / Accepted: 17 August 2006 / Published online: 18 October 2006

(C) Springer-Verlag 2006

\begin{abstract}
Objective The purpose of this study was to investigate the role of serotonin (5-HT) in the effects of oral 3,4methylenedioxymethamphetamine (MDMA) in humans. Materials and methods The subjective and physiological effects of $1.5 \mathrm{mg} / \mathrm{kg}$ MDMA were evaluated after $20 \mathrm{mg}$ fluoxetine in eight recreational MDMA users in a doubleblind, placebo-controlled study. During phase 1, participants were maintained on placebo for at least 5 days and tested with MDMA and placebo on separate sessions. In phase 2, the procedure was the same except fluoxetine was administered daily for at least 5 days. During sessions, placebo or fluoxetine was given $1 \mathrm{~h}$ before the session drug and effects were measured over the next $7 \mathrm{~h}$.

Results MDMA increased positive-like subjective effects on all the Addiction Research Center Inventory scales; Arousal, Elation, Positive Mood, and Vigor on the Profile of Mood States; Drug Liking, Friendly, Good Drug Effect, High, Stimulated, and Talkative on the Visual Analog Scale; and End-of-Session Liking and Crossover Point on the Multiple Choice Procedure. MDMA also increased measures of anxiety. On the Hallucinogenic Rating Scale, all scales except Volition were increased. MDMA also increased blood pressure and heart rate. Fluoxetine treatment attenuated most of the positive-like subjective effects including the Affect and Soma scales of the Hallucinogen Rating Scale. In addition, heart rate but not blood pressure increases were reduced.
\end{abstract}

M. Tancer $\cdot$ C.-E. Johanson $(\bowtie)$

Department of Psychiatry and Behavioral Neurosciences,

Wayne State University,

2761 E. Jefferson St.,

Detroit, MI 48207, USA

e-mail: cjohans@med.wayne.edu
Conclusions These results suggest that blockade of 5-HT reuptake by fluoxetine can dampen the effects of MDMA and further supports the role of 5-HT in its behavioral effects in humans.

Keywords 3,4-Methylenedioxymethamphetamine .

Fluoxetine · Humans · Subjective effects .

Physiological effects

\section{Introduction}

The behavioral pharmacology of 3,4-methylenedioxymethamphetamine (MDMA or ecstasy), a drug that has emerged as a significant drug of abuse over the last decade, has been studied in both nonhuman species and humans (see review by Green et al. 2003). MDMA is a phenylethylamine related structurally to both the amphetamines and mescaline (Green et al. 2003). In an attempt to differentiate the relative roles of the different neurotransmitter systems in the acute effects of MDMA, a variety of studies have been done in animals. In studies using measures of in vitro and in vivo neurochemistry, MDMA has been shown to be a potent releaser of both serotonin (5-HT) and dopamine (DA) (Cole and Sumnall 2003a,b; Green et al. 2003; Koch and Galloway 1997; Schmidt et al. 1987; White et al. 1996). Behavioral studies have been conducted using self-administration and drug discrimination procedures. While there are studies of the mediation of the reinforcing effects of MDMA in nonhuman primates (e.g., Fantegrossi et al. 2002), animal studies in rats, pigeons, and rhesus monkeys have largely focused on the discriminative stimulus effects of MDMA as a model of its subjective effects in humans and often considered a marker for 
reinforcing effects and hence related to abuse (Baker and Taylor 1997). These studies have determined that both amphetamine and 5-HT-mediated drugs, including fenfluramine and LSD, substitute in animals trained to discriminate MDMA from placebo and vice versa (Baker et al. 1995; Baker and Taylor 1997; Evans and Johanson 1986; Goodwin and Baker 2000; Goodwin et al. 2003; Kamien et al. 1986; Oberlender and Nichols 1988; Schechter 1986). Studies using a three-way discrimination to more finely differentiate MDMA's effects have demonstrated a pattern of results using substitution tests and pretreatments with DA and 5-HT antagonists suggesting that MDMAs discriminative stimulus effects are more 5HT-like, although DA systems may also be involved (Goodwin and Baker 2000; Goodwin et al. 2003).

Several studies in humans have shown that the acute administration of MDMA produces a unique profile of subjective effects suggesting an interaction between dopaminergic and serotonergic systems in mediating these effects (Cami et al. 2000; Tancer and Johanson 2001, 2003; Vollenweider et al. 1998). Tancer and Johanson $(2001,2003)$ compared the subjective effects of a range of doses of MDMA to both $d$-amphetamine, a prototypic dopaminergic drug, and metachlorophenylpiperazine (mCPP), a 5-HT-releasing agent. These studies demonstrated that the profile of reinforcing and subjective effects of MDMA was similar to both $d$-amphetamine and mCPP. These investigators also conducted a three-way drug discrimination study similar to those conducted in rats (Johanson et al. 2006). They trained humans to discriminate among $d$-amphetamine, $\mathrm{mCPP}$, and placebo and found that half of the participants discriminated 1 and $1.5 \mathrm{mg} / \mathrm{kg}$ MDMA as $d$-amphetamine and half as mCPP (Johanson et al. 2006). In addition, the subjective effects reported showed that MDMA did indeed have a mixed profile as shown in previous studies.

Another strategy for determining the role of neurotransmitters is to manipulate the actions of the drug with agonists and antagonist drugs and measure changes in the targeted behavior. As noted above, drug discrimination studies in nonhumans using this strategy have led to the conclusion that MDMA is mediated by both DA and 5-HT. In humans, these studies are relatively difficult to conduct as highly specific agonists and antagonists are often not available for administration to humans. Nevertheless, Liechti et al. (2000a,b) have done several studies implicating a prominent role for 5-HT in the actions of MDMA in humans using acute administration of a 5- $\mathrm{HT}_{2}$ antagonist, ketanserin, and an SSRI, citalopram. However, this group also demonstrated that haloperidol, a DA receptor antagonist, also could modify the subjective effects of MDMA (Liechti and Vollenweider 2000a). In the present study, these results were expanded using fluoxetine, another SSRI, which has been shown to antagonize the effects of MDMA in animal studies (Baumann et al. 2005; Berger et al. 1992; Mechan et al. 2002), most likely due to its blockade of MDMA's access to the 5-HT transporter, preventing a release of 5-HT.

\section{Materials and methods}

\section{Participants}

Participants who were recruited were between 18 and 35 years of age, had a minimum of a high school education or GED, had no medical condition that precluded participation, and were under $91 \mathrm{~kg}$. In addition, they had to have a history of stimulant recreational drug use (at least six times) including previous MDMA use (at least three times) with at least one use in the last 6 months. No candidate with a current or past Axis I diagnosis including drug or alcohol dependence disorder, other than nicotine dependence, was eligible. The exception was that drug or alcohol abuse disorder was not exclusionary if at least a year had passed since remission. Candidates were excluded if lifetime recreational use of psychomotor stimulants, opiates, phencyclidine, or sedatives exceeded 50 times. Women could not be pregnant or lactating. The study was approved by the Wayne State University Human Investigation Committee, and participants were reimbursed for their participation.

Potential participants attended a screening interview to determine eligibility. During this interview, the screening procedure and the study were first described. After asking any questions and passing a true-false quiz that probed the candidate's understanding of the protocol, the candidate and investigator signed the consent form in the presence of a witness. To determine eligibility, participants had a physical exam, submitted a blood and urine sample for routine testing, received an EKG, and filled out several questionnaires about their medical and drug-use history. To evaluate psychiatric status, a master's level psychologist administered the Structured Clinical Interview for Diagnostic and Statistical Manual (SCID-DSM-IV; First et al. 1996). The study purpose was explained, and participants were told that they might receive a stimulant, sedative, antidepressant, empathogen (MDMA or MDA), or a placebo.

Participants were instructed not to take any drugs, including recreational drugs, between sessions and alcohol for $12 \mathrm{~h}$ before a session. Urine drug and breath alcohol tests were conducted before every session to assure that these restrictions had been followed. Participants were allowed to consume their usual amounts of caffeine and nicotine. 
Procedure

The protocol consisted of two phases and utilized a placebo-controlled, within-subject crossover design. Drugs were administered under double-blind conditions, and sessions were separated by at least $48 \mathrm{~h}$. Sessions were conducted in a comfortable laboratory environment and began at approximately the same time each session. One to four individuals could participate at any one time. The other individuals may or may not have been participating in the same protocol. The consumption of caffeinated beverages was not allowed during the session. Smoking was allowed except for a 30-min period before drug ingestion and 30 min before each evaluation.

Participants reported to the laboratory for a total of six sessions. As soon as they arrived, breath alcohol levels were obtained to verify that they were alcohol-free (AlcoSensor III, Intoximeters), and urine was tested for the presence of cocaine, amphetamines, opiates, benzodiazepines, and barbiturates using fluorescence polarization immunoassay (Abbott $\mathrm{ADx}{ }^{\circledR}$ analyzer and standard reagents). Sessions were rescheduled if the breath or urine test detected recent drug use. Pregnancy tests were also performed on urine specimens from woman participants.

The effects of placebo and $1.5 \mathrm{mg} / \mathrm{kg}$ MDMA were assessed under placebo and $20 \mathrm{mg}$ /day fluoxetine maintenance conditions. The two drug administration sessions occurred between 5 and 11 days after the initiation of the maintenance condition. The order of drug administration across these two sessions was counterbalanced. At least $48 \mathrm{~h}$ after the second session of each maintenance condition, there was a lottery session (see description under "Multiple Choice Procedure" below). Placebo maintenance was always tested first because of the long half-life of fluoxetine. However, neither the participant nor the research staff was aware of this fixed sequence. The daily supplies of placebo and fluoxetine were given to the participant on day 1 and after each session for the days when experimental sessions were not conducted. Participants were required to telephone the laboratory every morning when they took the capsule on these nonexperimental session days.

Experimental sessions were $8 \mathrm{~h}$ in duration. After obtaining the battery of baseline physiological and subjective effects assessments (see below), the placebo or fluoxetine capsule was administered with water. An hour later, a second battery of assessments was made, and another capsule was administered containing MDMA or placebo. Physiological signs were assessed every $30 \mathrm{~min}$ for the remaining $7 \mathrm{~h}$, and subjective effects were collected every hour. At the end of the session, the Multiple Choice Procedure and an End-of-Session Questionnaire were given (see below), and participants were allowed to leave if they were free of any drug effect that would interfere with functioning.
Subjective effects measures

\section{Addiction Research Center Inventory (ARCI)}

Martin et al. (1971) have compiled a shortened version (49 true-false items) from the 550-item ARCI that is separated into five scales (Amphetamine [A], Benzedrine Group [BG], Lysergic Acid Diethylamide [LSD], MorphineBenzedrine Group [MBG], Pentobarbital-Chlorpromazine-Alcohol Group). Participants indicated by circling $\mathrm{T}$ for true and $\mathrm{F}$ for false whether the statement represented how they felt.

\section{Profile of Mood States (POMS)}

This version (modified from McNair et al. 1971) consists of 72 adjectives commonly used to describe mood states and has been factor-analyzed into eight scales (Anger, Anxiety, Confusion, Depression, Elation, Fatigue, Friendliness, Vigor). Two unvalidated scales have been derived as well (Arousal and Positive Mood). Participants indicated how they felt at the moment in relation to each of the adjectives from 0 (not at all) to 4 (extremely).

\section{Visual Analog Scales (VAS)}

The VAS consisted of a series of 19 horizontal 100-mm lines, each labeled with an adjective (Alert, Anxious, Bad Drug Effect, Confusion, Down, Friendly, Good Drug Effect, High, Hungry, Irritable, Liking, Miserable, On Edge, Sedated, Self-Conscience, Social, Stimulated, Talkative, Tired). Participants were instructed to place a mark on each line indicating how they felt at the moment from "not at all" to "extremely".

\section{Hallucinogen Rating Scale (HRS)}

This scale was developed and validated by Strassman et al. (1994) for measuring hallucinogenic symptoms after dimethyltryptamine administration. The HRS identifies six domains that purportedly describe hallucinogenic experiences. Each of the items is a phrase or a single word, and participants were asked to rate how or what they felt from 0 (not at all) to 4 (extremely). The six domains (and the number of items per domain) include: (a) somesthesia (13 items; e.g., "a rush"; "body feels different"; "feeling removed, detached, separated from body"); (b) affect (17 items; e.g., "anxious"; "awe"; "change in feelings of closeness of people in room"); (c) perception (17 items; e.g., "change in skin sensitivity"; "a sound or sounds accompanying the experiment"; "room overlaid with visual pattern"); (d) cognition (12 items; e.g., "new thoughts or insights"; "change in rate of thinking"; "change in sense of sanity"); (e) volition (eight items; e.g., 
"able to "let go"; "able to focus attention"; "in control"; all of which are reversed scored); and (f) intensity (three items; e.g., "waxing and waning of the experience"; "intensity"; "high"). One of the items on the affect scale and six of the items on the volition scale are reversed scored. The characteristics of the questions proscribe its administration before any capsule administration.

\section{Multiple-Choice Procedure (MCP)}

The MCP (Griffiths et al. 1993) was used to assess the reinforcing effects of MDMA and placebo at the end of sessions under both maintenance conditions. Participants were required to make a series of 20 discrete choices between the capsule they received during that session vs 20 ascending values of money (from give up $\$ 5$ to receive $\$ 5$ ). The money value at which participants stop choosing drug and start choosing money is referred to as the "crossover point". Participants were informed that one choice from the MCP (total of 40 across the two sessions) would be reinforced during session 3 or 6 , which were called lottery sessions. At that time, participants were presented with a bowl containing 40 numbered poker chips; one chip corresponded with each choice between drug and money amounts on the MCP during sessions $1-2$ or $4-6$. The participant randomly picked one poker chip out of the bowl, and the choice indicated by the number on the chip (money or drug) was reinforced with the presentation of either the indicated amount of money (or if "give up", that amount was subtracted from their earnings) or the indicated drug. Participants remained in the laboratory for the entire 8-h session regardless of whether they received a drug capsule or money. Vital signs were monitored hourly for safety reasons but were not used in any analysis.

\section{End-of-Session Liking Questionnaire}

At the end of every session except 3 and 6 , participants were asked to indicate how much they liked the drug overall on a VAS similar to those described above [End of Session (EOS) Liking].

\section{Data analyses}

Peak drug effects were determined for the physiological and subjective effects (POMS, VAS, ARCI, and HRS) of placebo and MDMA under the two maintenance conditions. A two-way ANOVA was performed with drug (placebo or MDMA) and condition (placebo or fluoxetine maintenance) as the within-subject factors. Similarly, a two-way ANOVA was performed on the EOS Liking and MCP comparing MDMA and placebo scores under the two conditions. Post hoc analyses were done using least significant differences.
For all analyses, violations of sphericity were addressed using the Huynh-Feldt adjustment factor. Significance levels were set at 0.05 .

Drug supplies

Racemic MDMA HCl was obtained from David Nichols (Purdue University) in powder form so that it was possible to administer doses on a milligram-per-kilogram basis. The measured powder was placed in gelatin capsules and filled with dextrose. Placebo capsules were filled with dextrose. All capsules were identical in color and size. Dosages were based on the salt weight.

\section{Results}

Participants

A total of 10 individuals met the criteria for inclusion and participated in at least one session. Two participants dropped out after the first phase, and the remaining eight completed the study. These included six white men and two white women, and their average age was 23.9 years (range 19-33). On average, they had used MDMA 28.6 times (range 4-66). All had used other recreational drugs but for each individual sedative, opiate and stimulant drug, including cocaine, lifetime use could not have exceeded 50 times because of the exclusion criterion (Table 1).

Subjective and physiological effects

There were several significant main drug effects (see Table 2). On the ARCI, MDMA increased scores on the Amphetamine, LSD, MBG, and BG scales and decreased scores on the PCAG scale relative to placebo. For POMS, there were significant increases for Arousal, Anxiety, Elation, Positive Mood, and Vigor. VAS ratings of Anxious, Drug Liking, Friendly, Good Drug Effect, High, Stimulated, and Talkative increased after MDMA. MDMA also increased HRS Affect,

Table 1 Percent of participants $(n=8)$ with lifetime or current use of recreational drugs

\begin{tabular}{ll}
\hline Drug & Lifetime use/current use \\
\hline Stimulants & $50 / 0$ \\
Cocaine & $62.5 / 25$ \\
Marijuana & $100 / 37.5$ \\
Other hallucinogen & $100 / 25$ \\
Sedatives & $37.5 / 0$ \\
Opiates & $37.5 / 12.5$ \\
Alcohol & $100 / 87.5$ \\
Cigarettes & $87.5 / 50$ \\
\hline
\end{tabular}


Table 2 Subjective and physiological effects of placebo and MDMA when maintained on placebo and fluoxetine (significant drug or condition $\times$ drug interactions*)

\begin{tabular}{|c|c|c|c|c|c|}
\hline & $\mathrm{Pl} / \mathrm{Pl}$ & P1/MDMA & $\mathrm{Fl} / \mathrm{Pl}$ & Fl/MDMA & ANOVA \\
\hline \multicolumn{6}{|l|}{ ARCI } \\
\hline Amphetamine & $2.8(0.5)$ & $6.3(0.7)^{\mathrm{a}}$ & $3.0(0.5)$ & $5.4(0.9)$ & $F(1,7)=10.9, p=0.013^{*}$ \\
\hline LSD & $3.9(0.4)$ & $6.5(0.3)^{\mathrm{a}}$ & $3.5(0.3)$ & $5.9(0.9)^{\mathrm{a}}$ & $F(1,7)=36.8, p=0.001^{*}$ \\
\hline MBG & $2.9(1.1)$ & $9.5(1.7)^{\mathrm{a}}$ & $2.6(0.9)$ & $6.3(1.8)^{\mathrm{b}}$ & $F(1,7)=9.7, p=0.017$ \\
\hline BG & $6.3(0.4)$ & $7.6(0.5)$ & $6.0(0)$ & $7.0(0.5)$ & $F(1,7)=8.3, p=0.023^{*}$ \\
\hline PCAG & $2.4(0.4)$ & $1.5(0.3)$ & $2.6(0.3)$ & $2.3(0.5)$ & $F(1,7)=6.5, p=0.038^{*}$ \\
\hline \multicolumn{6}{|l|}{ POMS } \\
\hline Arousal & $1.1(0.2)$ & $2.4(0.3)^{\mathrm{a}}$ & $1.0(0.3)$ & $1.4(0.3)^{\mathrm{b}}$ & $F(1,7)=16.1, p=0.005$ \\
\hline Anxiety & $0.4(0.04)$ & $1.0(0.1)^{\mathrm{a}}$ & $0.3(0.08)$ & $0.7(0.2)$ & $F(1,7)=15.7, p=0.005^{*}$ \\
\hline Elation & $1.1(0.2)$ & $2.4(0.3)^{\mathrm{a}}$ & $1.1(0.2)$ & $1.7(0.2)^{\mathrm{b}}$ & $F(1,7)=14.0, p=0.007$ \\
\hline Positive Mood & $1.1(0.2)$ & $2.4(0.3)^{\mathrm{a}}$ & $1.1(0.2)$ & $1.6(0.2)^{\mathrm{b}}$ & $F(1,7)=15.3, p=0.006$ \\
\hline Vigor & $1.2(0.2)$ & $2.2(0.2)^{\mathrm{a}}$ & $1.0(0.2)$ & $1.3(0.3)^{\mathrm{b}}$ & $F(1,7)=6.5, p=0.038$ \\
\hline \multicolumn{6}{|l|}{ VAS } \\
\hline Anxious & $3.6(1.9)$ & $44.8(14.9)^{\mathrm{a}}$ & $0.3(0.2)$ & $21.6(9.1)^{\mathrm{a}}$ & $F(1,7)=7.7, p=0.027^{*}$ \\
\hline Drug Liking & $5.1(2.8)$ & $86.5(4.0)^{\mathrm{a}}$ & $11.1(5.7)$ & $59.5(12.4)^{\mathrm{a}, \mathrm{b}}$ & $F(1,7)=6.6, p=0.037$ \\
\hline Friendly & $48.3(9.2)$ & $82.8(6.3)^{\mathrm{a}}$ & $54.5(9.3)$ & $66.9(7.2)$ & $F(1,7)=7.9, p=0.026^{*}$ \\
\hline Good Drug Effect & $9.0(4.1)$ & $76.9(6.1)^{\mathrm{a}}$ & $10.3(5.3)$ & $55.3(8.8)^{\mathrm{a}}$ & $F(1,7)=72.2, p<0.001 *$ \\
\hline High & $2.3(1.5)$ & $71.8(11.0)^{\mathrm{a}}$ & $4.4(3.3)$ & $37.6(8.6)^{\mathrm{a}, \mathrm{b}}$ & $F(1,7)=14.5, p=0.007$ \\
\hline Stimulated & $4.8(1.9)$ & $71.9(10.9)^{\mathrm{a}}$ & $3.0(1.9)$ & $43.1(9.8)^{\mathrm{a}, \mathrm{b}}$ & $F(1,7)=9.8, p=0.017$ \\
\hline Talkative & $35.6(9.1)$ & $70.0(7.6)^{\mathrm{a}}$ & $31.5(9.7)$ & $49.0(8.9)$ & $F(1,7)=8.4, p=0.023^{*}$ \\
\hline \multicolumn{6}{|l|}{ HRS } \\
\hline Affect & $0.4(0.1)$ & $1.2(0.2)^{\mathrm{a}}$ & $0.4(0.1)$ & $0.8(0.2)^{\mathrm{b}}$ & $F(1,7)=9.1, p=0.019^{*}$ \\
\hline Intensity & $0.5(0.2)$ & $2.1(0.4)^{\mathrm{a}}$ & $0.3(0.2)$ & $1.3(0.3)^{\mathrm{a}}$ & $F(1,7)=29.7, p=0.001^{*}$ \\
\hline Cognition & $0.1(0.1)$ & $0.7(0.2)^{\mathrm{a}}$ & $0.2(0.1)$ & $0.6(0.2)$ & $F(1,7)=7.8, p=0.027^{*}$ \\
\hline Perception & $0.1(0.03)$ & $0.6(0.3)$ & $0.03(0.02)$ & $0.3(0.1)$ & $F(1,7)=6.5, p=0.038$ \\
\hline Soma & $0.1(0.03)$ & $1.2(0.2)^{\mathrm{a}}$ & $0.1(0.1)$ & $0.7(0.1)^{\mathrm{a}, \mathrm{b}}$ & $F(1,7)=118.3, p<0.001$ \\
\hline MCP & $0.9(0.7)$ & $3.6(0.9)^{\mathrm{a}}$ & $0.8(0.9)$ & $1.3(1.0)$ & $F(1,7)=6.2, p=0.042$ \\
\hline EOS Liking & $23.8(12.1)$ & $82.9(5.0)^{\mathrm{a}}$ & $18.5(6.4)$ & $58.6(12.0)^{\mathrm{a}, \mathrm{b}}$ & $F(1,7)=44.0, p=0.001^{*}$ \\
\hline \multicolumn{6}{|l|}{ Vitals } \\
\hline Systolic BP & $125.4(4.1)$ & $154.6(4.9)^{\mathrm{a}}$ & $129.0(4.4)$ & $148.1(4.0)^{\mathrm{a}}$ & $F(1,7)=36.4, p=0.001^{*}$ \\
\hline Diastolic BP & $73.6(3.8)$ & $86.6(2.7)^{\mathrm{a}}$ & $68.5(3.5)$ & $84.8(3.3)^{\mathrm{a}}$ & $F(1,7)=49.0, p<0.001 *$ \\
\hline Heart Rate & $77.7(5.5)$ & $101.3(4.7)^{\mathrm{a}}$ & $73.0(3.1)$ & $86.5(2.9)^{\mathrm{a}, \mathrm{b}}$ & $F(1,7)=19.0, p=0.003$ \\
\hline
\end{tabular}

For measures taken repeatedly over the session (all but MCP and EOS Liking), values are peak effects [Mean (S.E.M.)]

The asterisk on the individual scales indicates that there was only a significant main drug effect. In all cases where there was a significant condition by drug interaction, there was also a significant main drug effect.

${ }^{a}$ MDMA significantly different $(p<0.05)$ from placebo under same pretreatment condition

${ }^{\mathrm{b}}$ MDMA after fluoxetine significantly different $(p<0.05)$ from MDMA after placebo

Cognition, Intensity, Perception, and Soma. Representative results are presented in Fig. 1. There were also significant drug effects on MCP crossover point and EOS Liking, and with both measures, the scores were higher for MDMA compared to placebo (Fig. 2). MDMA also increased heart rate and systolic and diastolic blood pressure (Fig. 3). In the post hoc analyses, in many cases where there was a significant main drug effect, this was due to significant differences in the effects of MDMA and placebo only when the maintenance condition was placebo (see Table 2). This was true for ARCI Amphetamine and MBG, all the POMS scales, VAS Friendly and Talkative, HRS Affect, Cognition and Soma scales, and MCP crossover point.

There were also several measures where there were significant drug $\times$ condition effects. The post hoc analyses revealed that maintenance on fluoxetine attenuated many of the effects of MDMA. This was not true for placebo, i.e., in no case were the effects of placebo administration different under the fluoxetine vs placebo maintenance condition. As seen in Table 2, fluoxetine decreased MDMA effects on ARCI MBG, POMS Arousal, Elation, Positive Mood and Vigor, VAS Drug Liking, High and Stimulated, HRS Affect and Soma, EOS Liking, and heart rate.

\section{Discussions}

The major finding of this study is that treatment with fluoxetine, a selective 5-HT reuptake inhibitor (SSRI), for at least 5 days attenuated the many, but not all, subjective 

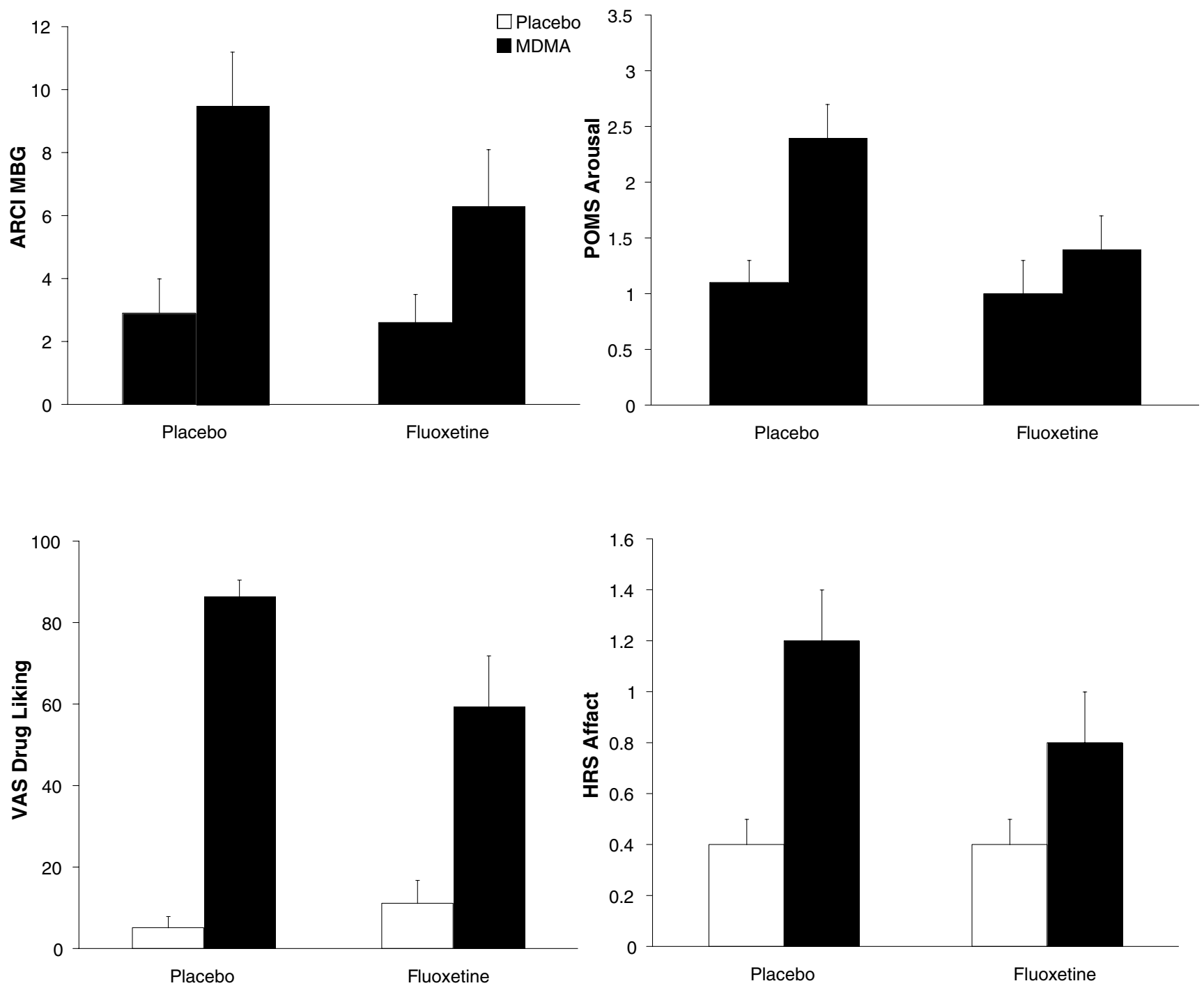

Fig. 1 Peak effects of placebo (open bars) and $1.5 \mathrm{mg} / \mathrm{kg}$ MDMA (closed bars) in combination with placebo pretreatment (left-hand side) or $20 \mathrm{mg}$ fluoxetine pretreatment (right-hand side) on ARCI

MBG (left top panel), POMS Arousal (right top panel), VAS Drug Liking (left bottom panel), and HRS Affect (right bottom panel). See Table 2 for post hoc analysis results

effects of MDMA. After pretreatment with placebo, MDMA produced changes in subjective and physiological effects remarkably similar to those found in previous studies (Harris et al. 2002; Johanson et al. 2006; Liechti et al. 2000a; Tancer and Johanson 2003). Many of these subjective effects are similar to those seen after the administration of other drugs of abuse such as amphetamine and may underlie MDMA's popularity as a recreational drug.

When fluoxetine was given for at least 5 days before the assessment of MDMA effects, many of the positive effects were attenuated. Fluoxetine itself had no effects on the measures of subjective effects as indicated by the similarity of effects of placebo under both maintenance conditions. The effects of MDMA on heart rate were also attenuated but blood pressure was not affected. It is also noteworthy that fluoxetine dampened the effects of MDMA on scales of the HRS, which have been postulated to reflect hallucino-

genic-like properties. These findings are consistent with the results reported by Liechti et al. (Liechti et al. 2000a; Liechti and Vollenweider 2000b) who administered intravenous citalopram, another SSRI, and demonstrated an attenuation of a wide range of MDMA effects, both subjective and physiological. In addition, Liechti et al. (2000b) demonstrated that a $5-\mathrm{HT}_{2}$ antagonist, ketanserin, also blocked subjective and physiological effects of MDMA in humans, implicating these receptors as important in the mediation of these effects. Like the findings in the present study, however, not all effects were blocked consistently in these two studies which, taken together, could be interpreted to mean that other systems play a role. It is interesting to note that McCann and Ricaurte (1993) published an article on antidotal reports from four individuals who claimed that ingestion of fluoxetine before MDMA use had no effects on its subjective effects. 


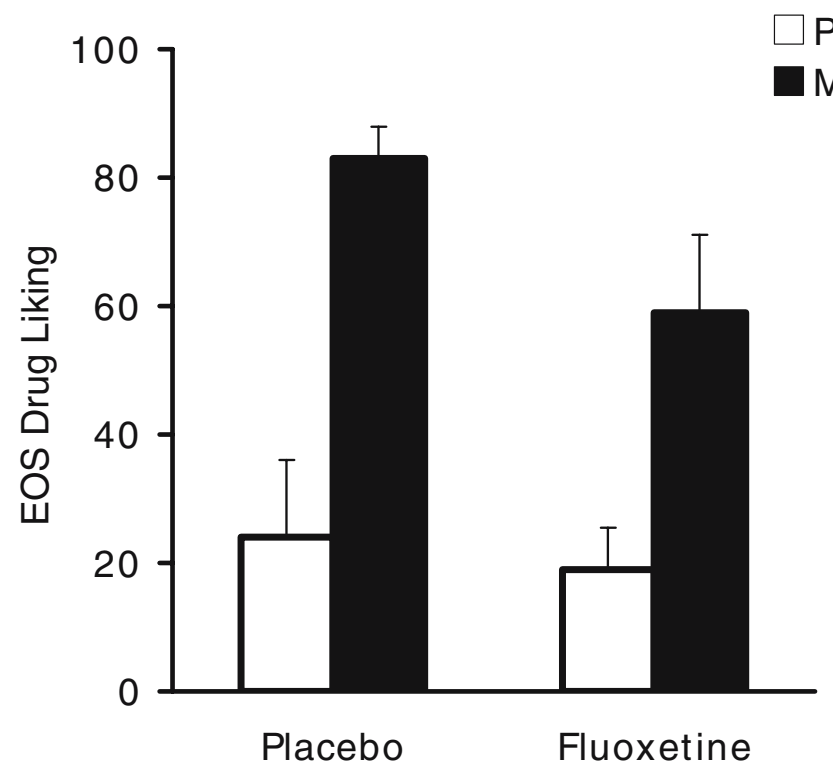

Fig. 2 The effects of placebo (open bars) and $1.5 \mathrm{mg} / \mathrm{kg}$ MDMA (closed bars) in combination with placebo pretreatment (left-hand side) or $20 \mathrm{mg}$ fluoxetine pretreatment (right-hand side) on End of

Nevertheless, these results in humans are consistent with the findings in rats and monkeys. For instance, preclinical studies have demonstrated that SSRIs block the ability of MDMA to release 5-HT presumably because they prevent the uptake of MDMA into 5-HT neurons (e.g., Hekmatpanah and Peroutka 1990; Rudnick and Wall 1992; Schmidt and Taylor 1990). Not surprisingly, then, SSRIs have been shown to block the behavioral effects of MDMA in rats (see review by Green et al. 2003). In addition, 5- $\mathrm{HT}_{2}$ antagonists also modify the effects of MDMA. For instance, Fantegrossi et al. (2002) showed that the reinforcing effects of MDMA were attenuated in rhesus monkey given ketanserin. Taken together, the findings clearly indicate the importance of 5HT systems in mediating the behavioral effects of MDMA in both animals and humans.

On the other hand, the failure to demonstrate complete attenuation across all measures seen in the present study and others may indicate that other neurotransmitters are also involved in the subjective and physiological effects of MDMA. For instance, there are preclinical studies demonstrating that DA plays a role in the effects of MDMA both at the molecular (Koch and Galloway 1997; Schmidt et al. 1987) and behavioral levels (Evans and Johanson 1986). An added complication is that there may be differences in neurochemical mediation as a function of the stereoisomers with the $\mathrm{S}(+)$-MDMA more dopaminergic and the $\mathrm{R}(-)$ MDMA more serotonergic (Baker et al. 1995; Glennon et al. 1988). Furthermore, Tancer and Johanson (2001, 2003) have demonstrated that in humans, MDMA shares many behavioral effects with $d$-amphetamine, and in a drug discrimination study where participants were trained to
Placebo

MDMA

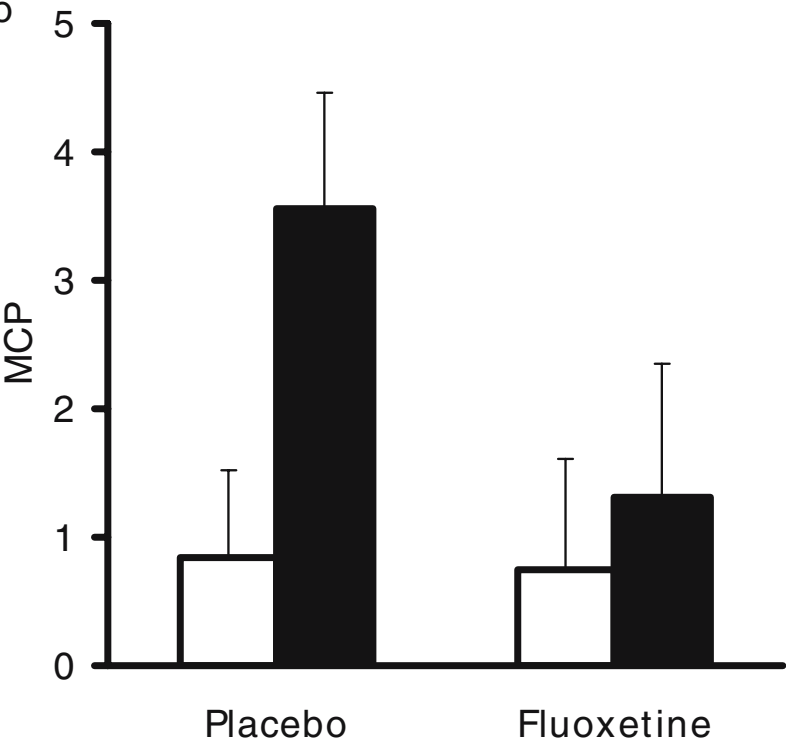

Session Drug Liking (left panel) and MCP Crossover point (right panel). See Table 2 for post hoc analysis results

discriminate among amphetamine and a 5-HT drug, $\mathrm{mCPP}$, half of the participants discriminated MDMA as amphetamine and half as mCPP (Johanson et al. 2006). However, studies in humans using DA antagonists have not only failed to block the subjective effects of classic dopaminergically mediated drugs, such as amphetamine (Brauer and de Wit 1996, 1997; Brauer et al. 1997) but in a study by Liechti and Vollenweider (2000a), haloperidol was also shown to change the subjective effects of MDMA from positive-like to more dysphoric, which they interpreted as a nonspecific interaction. Unfortunately, these results are somewhat difficult to interpret, and the role of DA in mediating the effects of both amphetamine and MDMA needs to be explored more thoroughly. Nevertheless, it seems clear that 5-HT plays a major role.

Several limitations of the study need to be acknowledged. First, the order of placebo and fluoxetine pretreatment was fixed, and the reduced effects of MDMA might be due to habituation. While this problem cannot be ruled out, in previous studies with multiple doses of MDMA, a diminution of effect over time has not been observed (Tancer and Johanson 2001, 2003). Second, only a single dose of fluoxetine was tested, and it is always possible that higher doses would be more effective. Third, in depressed individuals, 5 days of treatment with SSRIs is usually not sufficient to produce behavioral changes and thus it might be argued that there would be more complete blockade of MDMA effects if fluoxetine had been administered over a longer period of time. However, amelioration of depressive symptoms may require neuroadaptational changes, which is unlikely the case with subjective effects of MDMA. It is 

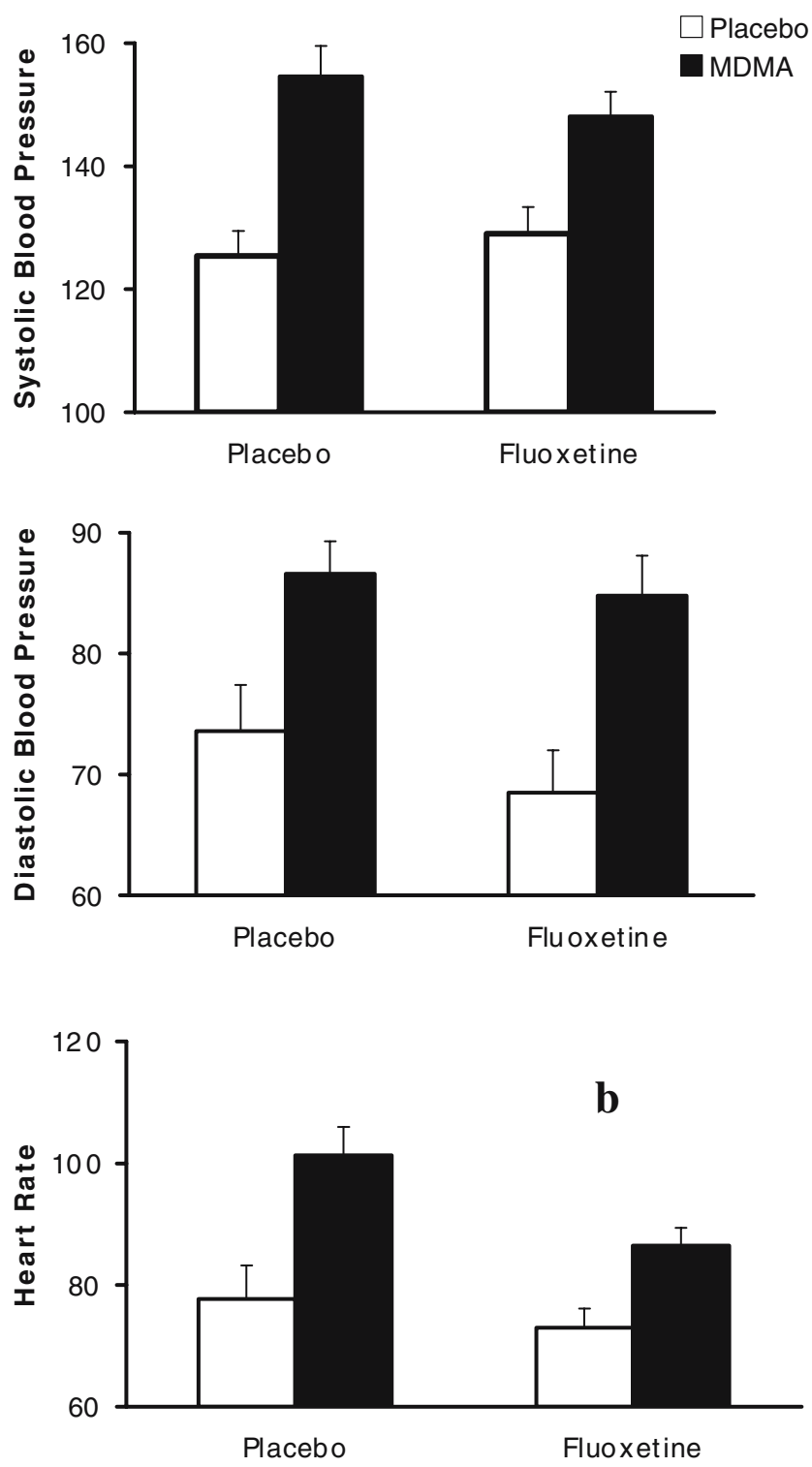

Fig. 3 Peak effects of placebo (open bars) and $1.5 \mathrm{mg} / \mathrm{kg}$ MDMA (closed bars) in combination with placebo pretreatment (left-hand side) or $20 \mathrm{mg}$ fluoxetine pretreatment (right-hand side) on systolic blood pressure (top panel), diastolic blood pressure (middle panel), and heart rate (bottom panel). See Table 2 for post hoc analysis results

also interesting to note that the attenuation observed was similar to the blockade noted by Liechti et al. (2000a) after acute citalopram administration, i.e., there was no indication that a longer duration of treatment in the present study resulted in a greater degree of blockade.

In conclusion, the present study demonstrated that many of the subjective effects of MDMA as well as heart rate increases could be attenuated by fluoxetine. While the degree of blockade was not complete, these results add to the substantive literature on the role of $5-\mathrm{HT}$ in the behavioral effects of MDMA in humans.
Acknowledgments The authors would like to thank Nancy Lockhart, Debra Kish, and Ken Bates for their assistance in conducting the study.

This research was support by a NIDA grant (KO8 DA00370 to MT) and Joe Young, Sr., funds from the State of Michigan.

\section{References}

Baker LE, Taylor MM (1997) Assessment of the MDA and MDMA optical isomers in a stimulant-hallucinogen discrimination. Pharmacol Biochem Behav 57:737-748

Baker LE, Broadbent J, Michael EK, Matthews PK, Metosh CA, Saunders RB, West WB, Appel JB (1995) Assessment of the discriminative stimulus effects of the optical isomers of ecstasy (3,4methylenedioxymethamphetamine; MDMA). Behav Pharmacol 6:263-275

Baumann MH, Clark RD, Budzynski AG, Partilla JS, Blough BE, Rothman RB (2005) N-substituted piperazines abused by humans mimic the molecular mechanism of 3,4-methylenedioxymethamphetamine (MDMA, or 'Ecstasy'). Neuropsychopharmacology 30:550-560

Berger UV, Gu XF, Azmitia EC (1992) The substituted amphetamines 3,4-methylenedioxymethamphetamine, methamphetamine, p-chloroamphetamine and fenfluramine induce 5-hydroxytryptamine release via a common mechanism blocked by fluoxetine and cocaine. Eur J Pharmacol 215:153-160

Brauer LH, de Wit H (1996) Subjective responses to d-amphetamine alone and after pimozide pretreatment in normal, healthy volunteers. Biol Psychiatry 39:26-32

Brauer LH, de Wit H (1997) High dose pimozide does not block amphetamine-induced euphoria in normal volunteers. Pharmacol Biochem Behav 56:265-272

Brauer LH, Goudie AJ, de Wit H (1997) Dopamine ligands and the stimulus effects of amphetamine: animal models versus human laboratory data. Psychopharmacology (Berl) 130:2-13

Cami J, Farre M, Mas M, Roset PN, Poudevida S, Mas A, San L, de la Torre R (2000) Human pharmacology of 3,4-methylenedioxymethamphetamine ("ecstasy"): psychomotor performance and subjective effects. J Clin Psychopharmacol 20:455-466

Cole JC, Sumnall HR (2003a) Altered states: the clinical effects of ecstasy. Pharmacol Ther 98:35-58

Cole JC, Sumnall HR (2003b) The pre-clinical behavioural pharmacology of 3,4-methylenedioxymethamphetamine (MDMA). Neurosci Biobehav Rev 27:199-217

Evans SM, Johanson CE (1986) Discriminative stimulus properties of $( \pm)$-3,4-methylenedioxymethamphetamine and ( \pm )-3,4-methylenedioxyamphetamine in pigeons. Drug Alcohol Depend 18:159-164

Fantegrossi WE, Ullrich T, Rice KC, Woods JH, Winger G (2002) 3,4Methylenedioxymethamphetamine (MDMA, "ecstasy") and its stereoisomers as reinforcers in rhesus monkeys: serotonergic involvement. Psychopharmacology (Berl) 161:356-364

First MB, Spitzer RL, Gibbon M, Williams JBW (1996) Structured clinical interview of DSM-IV axis I disorders - patient edition (SCID I/P, Version 2). Biometrics Research Department, NY State Psychiatric Institute, New York

Glennon RA, Yousif M, Patrick G (1988) Stimulus properties of 1(3,4-methylenedioxyphenyl)-2-aminopropane (MDA) analogs. Pharmacol Biochem Behav 29:443-449

Goodwin AK, Baker LE (2000) A three-choice discrimination procedure dissociates the discriminative stimulus effects of $d$ amphetamine and $( \pm)$-MDMA in rats. Exp Clin Psychopharmacol $8: 415-423$ 
Goodwin AK, Pynnonen DM, Baker LE (2003) Serotonergicdopaminergic mediation of MDMA's discriminative stimulus effects in a three-choice discrimination. Pharmacol Biochem Behav 74:987-995

Green AR, Mechan AO, Elliott JM, O'Shea E, Colado MI (2003) The pharmacology and clinical pharmacology of 3,4-methylenedioxymethamphetamine (MDMA, "ecstasy"). Pharmacol Rev 55:463-508

Griffiths RR, Troisi JR, Silverman K, Mumford GK (1993) Multiplechoice procedure: an efficient approach for investigating drug reinforcement in humans. Behav Pharmacol 4:3-13

Harris DS, Baggott M, Mendelson JH, Mendelson JE, Jones RT (2002) Subjective and hormonal effects of 3,4-methylenedioxymethamphetamine (MDMA) in humans. Psychopharmacology (Berl) 162:396-405

Hekmatpanah CR, Peroutka SJ (1990) 5-Hydroxytryptamine uptake blockers attenuate the 5-hydroxytryptamine-releasing effect of 3,4-methylenedioxymethamphetamine and related agents. Eur J Pharmacol 177:95-98

Johanson C-E, Kilbey M, Gatchalian K, Tancer M (2006) Discriminative stimulus effects of 3,4-methylenedioxymethamphetamine (MDMA) in humans trained to discriminate among d-amphetamine, metachlorophenylpiperazine and placebo. Drug Alcohol Depend 81:27-36

Kamien JB, Johanson CE, Schuster CR, Woolverton WL (1986) The effects of $( \pm)$-methylenedioxymethamphetamine and $( \pm)$ methylenedioxyamphetamine in monkeys trained to discriminate $(+)$-amphetamine from saline. Drug Alcohol Depend 18: $139-147$

Koch S, Galloway MP (1997) MDMA induced dopamine release in vivo: role of endogenous serotonin. J Neural Transm 104:135-146

Liechti ME, Vollenweider FX (2000a) Acute psychological and physiological effects of MDMA ("Ecstasy") after haloperidol pretreatment in healthy humans. Eur Neuropsychopharmacol 10:289-295

Liechti ME, Vollenweider FX (2000b) The serotonin uptake inhibitor citalopram reduces acute cardiovascular and vegetative effects of 3,4-methylenedioxymethamphetamine ('Ecstasy') in healthy volunteers. J Psychopharmacol 14:269-274

Liechti ME, Baumann C, Gamma A, Vollenweider FX (2000a) Acute psychological effects of 3,4-methylenedioxymethamphetamine (MDMA, "Ecstasy") are attenuated by the serotonin uptake inhibitor citalopram. Neuropsychopharmacology 22:513-521

Liechti ME, Saur MR, Gamma A, Hell D, Vollenweider FX (2000b) Psychological and physiological effects of MDMA ("Ecstasy") after pretreatment with the 5-HT(2) antagonist ketanserin in healthy humans. Neuropsychopharmacology 23:396-404
Martin WR, Sloan JW, Sapira JD, Jasinski DR (1971) Physiologic, subjective and behavioral effects of amphetamine, ephedrine, phemetrazine, and methylphenidate in man. Clin Pharmacol Ther $12: 245-258$

McCann UD, Ricaurte GA (1993) Reinforcing subjective effects of ( \pm ) 3,4-methylenedioxymethamphetamine ("ecstasy") may be separable from its neurotoxic actions: clinical evidence. J Clin Psychopharmacol 13:214-217

McNair DM, Lorr M, Droppleman LF (1971) Manual for the profile of mood states. Educational and Industrial Testing Service, San Diego, CA

Mechan AO, Esteban B, O'Shea E, Elliott JM, Colado MI, Green AR (2002) The pharmacology of the acute hyperthermic response that follows administration of 3,4-methylenedioxymethamphetamine (MDMA, 'ecstasy') to rats. Br J Pharmacol 135:170-180

Oberlender R, Nichols DE (1988) Drug discrimination studies with MDMA and amphetamine. Psychopharmacology 95:71-76

Rudnick G, Wall SC (1992) The molecular mechanism of "ecstasy" [3,4-methylenedioxy-methamphetamine (MDMA)]: serotonin transporters are targets for MDMA-induced serotonin release. Proc Natl Acad Sci USA 89:1817-1821

Schechter MD (1986) Discriminative profile of MDMA. Pharmacol Biochem Behav 24:1533-1537

Schmidt CJ, Taylor VL (1990) Reversal of the acute effects of 3,4methylenedioxymethamphetamine by 5 -HT uptake inhibitors. Eur J Pharmacol 181:133-136

Schmidt CJ, Levin JA, Lovenberg W (1987) In vitro and in vivo neurochemical effects of methylenedioxymethamphetamine on striatal monoaminergic systems in the rat brain. Biochem Pharmacol 36:747-755

Strassman RJ, Qualls CR, Uhlenhuth EH, Kellner RK (1994) Dose response study of NN-dimethyltryptamine in humans. Arch Gen Psychiatry 51:98-108

Tancer ME, Johanson CE (2001) The subjective effects of MDMA and mCPP in moderate MDMA users. Drug Alcohol Depend 65:97-101

Tancer M, Johanson CE (2003) Reinforcing, subjective, and physiological effects of MDMA in humans: a comparison with damphetamine and mCPP. Drug Alcohol Depend 72:33-44

Vollenweider FX, Gamma A, Liechti M, Huber T (1998) Psychological and cardiovascular effects and short-term sequelae of MDMA ("ecstasy") in MDMA-naive healthy volunteers. Neuropsychopharmacology 19:241-251

White SR, Obradovic T, Imel KM, Wheaton MJ (1996) The effects of methylenedioxymethamphetamine (MDMA, "Ecstasy") on monoaminergic neurotransmission in the central nervous system. Prog Neurobiol 49:455-479 